\title{
Intestinal Parasitic Investigation in Temple Rhesus Monkeys of Kathmandu
}

\author{
Anwita Jha ${ }^{1}$ and Mukesh K. Chalise ${ }^{2}$ \\ Rebati M. Shrestha and Kedar Karki ${ }^{3}$ \\ Corresponding author: Mukesh Chalise \\ Email : mukesh57@hotmail.com
}

\begin{abstract}
:
The rhesus monkeys (Macaca mulatta) of Kathmandu come into frequent contact with humans and due to their habit of residing in the religious and parkland of human proximity, there is possibility of zoonotic and anthroponotic disease transmission between them. So, a prevalence survey of gastrointestinal parasites of these monkeys was conducted during April and May 2005 in three temples Pashupatinath, Swyombhunath and Tripureshwor. Total 121 fresh faecal samples, were collected randomly from these areas that were about fifteen percent of total monkey population. The faecal samples were analyzed by direct smear and concentration methods. The overall parasitization rate was $76.86 \%$ with the highest in Pashupatinath (86\%) followed by Swyombhunath (74\%) and Tripureshwor (61.9\%). About 27.96\% had single infection while $72.04 \%$ had mixed infection. This showed that the presence of one parasite reduced the immunity of the host as a result multiple infections existed. Parasite identifications were based upon the size and appearance of trophozoites, cysts, eggs and larvae of parasites. Both protozoan and helminthes parasites were observed in varying rates in three temples. Three species of protozoa and ten species of helminths were detected by microscopical examination of faecal samples. Human is always prone to be infected by most of these parasites so they are of zoonotic importance. The study will enrich the information on temple monkeys and will support their ecological management in human proximity.
\end{abstract}

Key words : Rhesus monkey, Intestinal, Parasites, Zoonotic diseases, Phylogentic relationship

\section{Introduction}

Parasites play a central role in ecosystem affecting the ecology and evolution of species interactions (Esch and Fernandez 1993), host population growth and regulation (Hudson et al 1998; Hochachka and Dhondt 2000) and community biodiversity (Hudson 2002). Parasites are integral part of the natural history of mammals and are always of interest. They

\footnotetext{
${ }^{1}$ Nepal Biodiversity Research Society, Lalitpur, NEPAL

${ }^{2}$ Central Department of Zoology, Kirtipur Tribhuvan University (TU)

${ }^{3}$ Central Veterinary Laboratory, Tripureshwor
} 
form an important, though usually overlooked, component of the biodiversity of ecosystem. Parasite affects almost each and every group of living organisms and it is not unusual for monkeys also because of their habit. Rhesus macaques (Macaca mulatta) constitute an integral part of biodiversity and cognizable link between humans and nature. Our ancient epics and plays also portray the relation of humans and monkeys which still exists. They are exceptionally adapted to co-existing with humans and thrive near human settlements in both urban and agricultural areas (Cawthon 2005). The rhesus monkeys, in the capital city Kathmandu, live in commensalisms close to human fostered by religious beliefs and kindness. In Kathmandu valley, about 1000 rhesus monkeys are inhabitants of major temple areas like Pashupatinath, Swyombhunath, Tripureshwor (Ram Mandir), etc. (Chalise \& Ghimire, 1998, Chalise, 2006). Monkeys of temple areas not only share the food but also the parasites of the human inhabitants. Their close phylogenetic relationship with the human results the high potential pathogen exchange (Cheng 1999). So, rhesus monkey population of Kathmandu, unexplored source of information regarding the zoonotic diseases, may provide recent status of intestinal parasites, both of zoonotic and anthroponotic importance.

As the rhesus monkey and human are very close regarding their physiologic and genetic characters, they also share infectious agents like intestinal parasites besides their food. Evidences show that many emerging parasitic diseases in human are originated from primates on one side and on the other side; there is a great risk of human pathogen transmission to free ranging primates (Jones-Engel, et al 2006). Though in Kathmandu valley, total population of Rhesus macaques has shown relatively stable numbers over a period of several years, biologists have pointed out their deteriorating health conditions due to adulterated food, polluted water and habitat encroachment, thereby increasing threat to the lives of the monkeys of Kathmandu valley.

This study helps to determine the current status of intestinal parasitic infections among the temple rhesus monkeys of Kathmandu and will shed light and overview on them. Therefore, it will provide a baseline for primatologists, veterinarians, ecologists, and others interested readers on their health conditions.

\section{Methodology}

The prevalence survey of gastrointestinal parasites was conducted during April and May 2005. Fresh faecal samples were collected during early morning in sterilized plastic sample tubes. A total of 121 fresh faecal samples, 50 from Pashupatinath, 50 from Swyombhunath and 21 from Tripureshwor were collected randomly that were about 15\% of total population of monkeys in these three areas. The samples were transferred and examined in Parasitological Lab of Central Veterinary Laboratory, Tripureshwor as soon as possible.

\section{Macroscopic Examination}

The specimens were examined with naked eye for the presence of colour, consistency, worm, tapeworm segments, blood and mucus etc during the time of collection in the field site. 


\section{Microscopic Examination}

The stool samples were examined with both direct smear and concentration methods. Wet mount preparations were made in normal saline and iodine and observed under microscope with 10X objective. The suspected objects were confirmed by observing with $40 \mathrm{X}$ objectives. Parasite identifications were based upon the size and appearance of trophozoites, cysts, eggs and larvae of parasites.

\section{Results}

The examination of collected 121 fecal samples divulged that the over all prevalence of intestinal parasites was $76.86 \%$. Among the three sample sites, the highest was in Pashupatinath $(86 \%, \mathrm{n}=43)$ followed by Swyombhunath $(74 \%, \mathrm{n}=37)$ and Tripureshwor $(61.9 \%, \mathrm{n}=13)$ without significant difference $(\mathrm{P}>0.005)$.

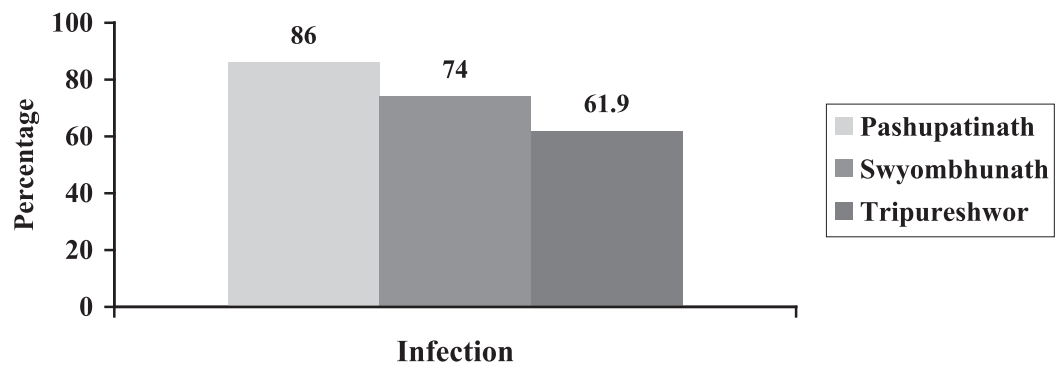

Fig 1: Overall Prevalence of Intestinal Parasites in Monkeys of Three areas.

\section{Intensity of Infection}

Regarding the intensity of infection, about 26 (27.96\%) had single infection, 37 (39.78\%) had double and $30(32.26 \%)$ had multiple infection. There was a case with the infection of 7 types of parasites in the Swyombhunath region.

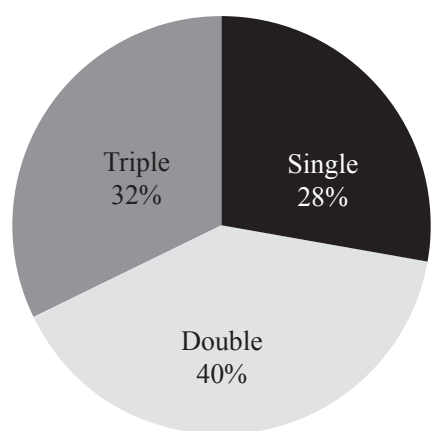

Fig 2: Intensity of Infection in investigated samples $(n=93)$. 
During the examination of faecal samples, overall 13 species of intestinal parasites were detected among which 3 species were protozoa and 10 species were helminths. Both the protozoan and helminthic parasites were found in varying rates in all three temples.

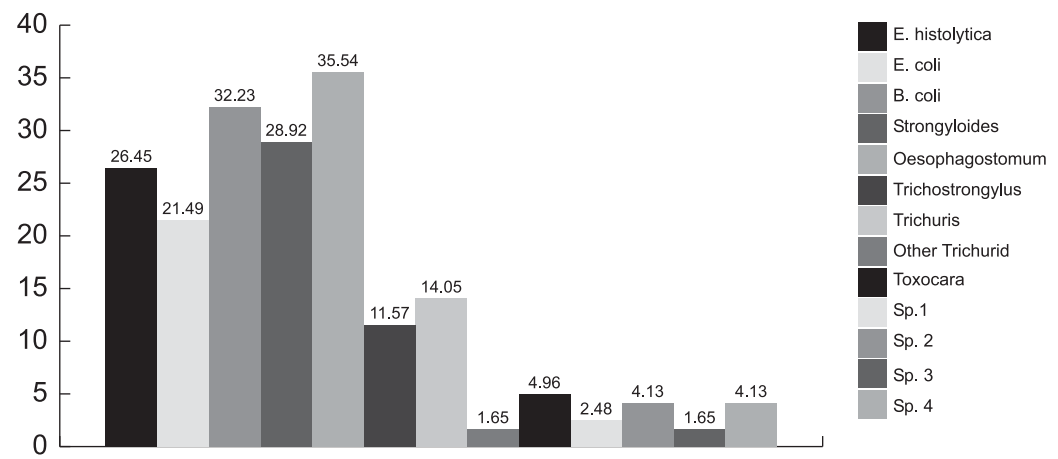

Fig 3: Percentages of Overall Prevalence of All the Thirteen Parasites

Overall prevalence showed (Tab 1) that the infection of Oesophagostomum was highest (35.54\%) followed by Balantidium coli (32.23\%), Strongyloides (28.92\%), E. histolytica (26.45\%), E. coli (21.49\%), Trichuris (14.05\%) and Trichostrongylus (11.57\%). Rest were comparatively less in number. Among the total infection $65(53.72 \%)$ had protozoan and 71 $(59.5 \%)$ had helminthic infection. But there was no significant difference $(\mathrm{P}>0.05)$ in the prevalence of Oesophagostomum, Trichostrongylus, Strongyloides, E. histolytica, E. coli, B. coli, and Trichuris in three temples.

Table No. 1: Prevalence of Specific Parasites in Three Temple areas

\begin{tabular}{|c|l|l|l|l|c|c|c|c|c|}
\hline \multirow{2}{*}{ SN } & \multicolumn{2}{|c|}{ Parasites } & \multicolumn{2}{|c|}{ Pashupatinath } & \multicolumn{2}{l|}{ Swyombhunath } & \multicolumn{2}{l|}{ Tripureshwor } & \multicolumn{2}{c|}{ Total } \\
\cline { 3 - 11 } & & No. & $\%$ & No. & $\%$ & No. & $\%$ & No. & $\%$ \\
\hline 1. & E. histolytica & 13 & 26 & 16 & 32 & 4 & 19.04 & 32 & 26.45 \\
\hline 2. & E. coli & 12 & 24 & 12 & 24 & 2 & 9.52 & 26 & 21.49 \\
\hline 3. & B. coli & 15 & 30 & 18 & 36 & 6 & 28.57 & 39 & 32.23 \\
\hline 4. & Strongyloides & 17 & 34 & 15 & 30 & 3 & 14.39 & 35 & 28.92 \\
\hline 5. & Oesophagostomum & 20 & 40 & 17 & 34 & 6 & 28.57 & 43 & 35.54 \\
\hline 6. & Trichostrongylus & 8 & 16 & 5 & 10 & 1 & 4.76 & 14 & 11.57 \\
\hline 7. & Trichuris & 6 & 12 & 7 & 14 & 4 & 19.04 & 17 & 14.05 \\
\hline 8. & Other Trichurid & - & - & 1 & 2 & 1 & 4.76 & 2 & 1.65 \\
\hline 9. & Toxocara & 2 & 4 & 4 & 8 & - & - & 6 & 4.96 \\
\hline 10. & Unknown sp. 1 & 2 & 4 & 1 & 2 & - & - & 3 & 2.48 \\
\hline
\end{tabular}




\begin{tabular}{|c|l|l|l|l|l|l|l|l|l|}
\hline SN & \multirow{2}{*}{ Parasites } & \multicolumn{2}{|c|}{ Pashupatinath } & \multicolumn{2}{|c|}{ Swyombhunath } & \multicolumn{2}{|c|}{ Tripureshwor } & \multicolumn{2}{c|}{ Total } \\
\cline { 3 - 12 } & & No. & $\%$ & No. & $\%$ & No. & $\%$ & No. & $\%$ \\
\hline 11. & Unknown sp. 2 & 1 & 2 & 3 & 6 & 1 & 4.76 & 5 & 4.13 \\
\hline 12. & Unknown sp. 3 & 1 & 2 & 1 & 2 & - & - & 2 & 1.65 \\
\hline 13. & Unknown sp. 4 & - & - & 2 & 4 & 3 & 14.29 & 5 & 4.13 \\
\hline
\end{tabular}

\section{Discussion}

Rhesus monkey population of Kathmandu, unexplored source of information regarding the zoonotic diseases, may provide recent status of intestinal parasites, both of zoonotic and anthroponotic importance. As the rhesus monkey and human are very close regarding their physiologic and genetic characters, they also share infectious agents like intestinal parasites besides their food.

The result of present study showed an overall infection rate of $76.86 \%$ for all intestinal parasites with $53.72 \%$ for protozoan and $59.5 \%$ for helminthic parasites. This study also showed that $28(23.41 \%)$ monkeys had no infection and whether it is due to very low parasitic burden so low parasitic output or they were really parasite free, this has not been clear because this study was based only on stool examination not on the necropsy. So the helminth parasites were also identified only up to the genus level.

This study also shows that there was no significant difference in infection rate $(\mathrm{P}>0.05)$ in three localities which might be possible because of similar type of habitat and feeding habit and also because they have to compete with similar kind of animals like dog and cow etc.

All the parasites except Toxocara in this study are in agreement with Soulsby (1982). He has listed Entamoeba, Balantidium, Strongyloides, Oesophagostomum, Trichostrongylus and Trichuris all as infecting non human primates. These parasites are common in non human primates (Baskin, Rand 2004 and Flynn 1973) supporting the result of present study.

Munene et al. (1998) has reported protozoan parasites, E. coli, E. histolytica, B. coli and helminthic parasites, Strongyloides, Trichuris, Oesophagostomum and Trichostrongylus in captive and wild trapped (WT) non human primates (Baboons, Vervets and Sykes) in Kenya. Mutani et al. (2003) has also recorded Strongyloides, Trichuris, Oesophagostomum and Trichostrongylus in Barbados green monkey (Cercopithecus aethiops sabaeus). These results are in concurrence with the present result.

Oesophagostomum was the most common parasite (35.54\%) followed by B. coli $(32.23 \%)$, Strongyloides (28.92\%), E. histolytica (26.45\%), E. coli $(21.49 \%)$, Trichuris $(14.05 \%)$ and Trichostrongylus (11.57\%). Rests were less common. Eberhard (1981) also showed Strongyloides (34\%), Trichuris (47\%) and E. histolytica (59\%) in outdoor breeding colony of Macaca mulatta and these parasites were also found in present study. Knezevich (1998) 
also found B. coli, Trichuris and Strongyloides in 141 free ranging macaques (M. mulatta) with the infection rate of $89 \%$ but diarrhoea was negligible (2\%) similar to present study with $76.86 \%$ infection with $6.61 \%$ diarrhoea cases.

Generally, Toxocara is the parasite of Canidae and Felidae family but its presence in these monkeys is not uncommon as both monkeys and dogs share food and shelter so, share pathogens also. So, it can be concluded from this study that the competitors also affect on the types and prevalence of intestinal parasites on these monkeys. For instance, the present study showed that the prevalence of Trichostrongylus, a common parasite of cattle, was high in the monkeys of Pashupatinath as they are more closely in contact with the cows than the rest two localities.

Regarding the intensity of infection, $27.96 \%$ monkeys had single infection, $39.78 \%$ had double and $32.26 \%$ had multiple infections. So, this study showed that $72.04 \%$ monkeys harboured more than one parasite and this high rate of transmission might be possible either due to high population density or due to favourable environmental conditions for parasites. All the parasites except Toxocara and Oesophagostomum recorded during this study are potential to attack human. Though Oesophagostomum has not been recorded from human in Nepal but has been reported from Ethiopia, Nigeria, Togo, Ghana, tropical Africa, Brazil, Malaysia and Indonesia etc. (Neafie et al.). Thus, it would be rational to consider these monkeys populations as the reservoir hosts of several intestinal parasites of human.

Finally, it is recommended that routine analysis of stool samples should be done by concerned organization/s which may prevent the outbreak of several human intestinal parasitic diseases in this valley during summer and rainy season.

\section{Conclusion}

The study reveals that the temple monkeys of Kathmandu are loaded by infectious protozoan and helminthes and non-infectious Toxocara parasites to human beings. It is recommended that they should be medically treated accordingly by concerned authorities and the prevalence of parasites to locals and temple goers should be publicized by different media.

The study for detail investigation should be initiated by government and other related and/or concerned organizations as monkeys are close to capital settlements. More than $20,00,000$ people have increased in the recent years in the valley and hence the chances of transmitting diseases are quite likely. 


\section{References}

Baskin, G.B. DVM. Tulane Regional Primate Research Centre. Covington, Louisiana: Tulane University

Cawthon, K.A. 2005 July 26. Primate Fact Sheets: Rhesus Macaque (Macaca mulatta) Taxonomy, Morphology and Ecology.

Chalise, M.K. and Ghimire, M. 1998. Non-human primate census in different parts of Nepal. Natural History Society of Nepal (pp 8(1-4):11-15).

Chalise, M.K. (2006). Primate census in different parts of Nepal. Journal of the University Campus TUTA, TU, Prospective on Higher Education. Vol. 2 \& 3: 35-41.

Cheng, T.C. 1999. General Parasitology. Second Edition. Academic Press, inc.

Eberhard, M.L.1981. Intestinal parasitism in an outdoor breeding colony of Macaca mulatta: Lab Anim. Sci. 31(3): 282-285.

Esch, G. and Fernandez, J.L. 1993.A Functional Biology of Parasitism: Ecological and Evolutionary Implications. London: Chapman and Hall.

Flynn, R.J. 1973. Parasites of Laboratory Animals.Ames: IOWA State University Press.

Hochachka,V.W. and Dhondt, A.A.2000. Density- dependent decline of host abundance resulting from a new infectious disease. Proc. Nat. Acad. Sci., 97:5303-5306.

Hudson, P.J., Dobson, A.P. and Newborn, D. 1998. Prevention of population cycles by parasitic removal. Science, 282:2256-2258.

Hudson, P.J., Rizzoli, A., Grenfell, B.T., Heesterbeek, H., and Dobson, A.P.2002. The Ecology of Wildlife Disease. Oxford, UK: Oxford University Press.

Jones-Engel, L., Engel, G .A., Schillaci, M.A., Heidrich J., Chalise, M .K. and_Kyes, R.C. 2006. Considering human-primate transmission of measles virus through the prism of risk analysis. American Journal of Primatology (Research Article), 68: 868-879.

Knezevich, M. 1998. Geophagy as a therapeutic mediator of endoparasitism in free-ranging group of rhesus macaques (Macaca mulatta). Am. J. Primatol, 44(1): 71-82.

Munene, E., Otsyula, M., Mbaabu, D.A., Mutahi, W.T., Murjuki S.M. and Muchemi G.M. 1998. Helminth and Protozoan gastro intestinal tract parasites in captive and wild-trapped African non-human primates. Vet Parasitol: 78(3):195-201.

Mutani, A. Rhynd, K., and Brown,G. 2003. A preliminary investigation on the gastrointestinal helminths of the Barbados green monkey, Cerapithecus aethiops sabaeus. Rev Inst. Med. trop S Paulo, 45(4): 193-195.

Neafie, R.C. and Marty, A.M. Pathology of Infectious Disease, Helminthiases. Armed Forced Institute of Pathology American Registry of Pathology. Volume 1.

Rand, M.S. 2004. Diseases of Non-Human Primates Research Animal Methods. VSC 443/543-Fall. Lecture notes for November 1, 2004.

RONAST. Newsletter of the Royal Nepal Academy of Science and Technology, Kathmandu, Nepal. April 2001.

Soulsby J.L. 1982. Helminthes, Arthropods and Protozoa of Domesticated Animals. $7^{\text {th }}$ Edition. London, ELBS. 